\title{
Effect of Insecticides and Plutella xylostella (Lepidoptera: Plutellidae) Genotype on a Predator and Parasitoid and Implications for the Evolution of Insecticide Resistance
}

\author{
XIAOXIA LIU, ${ }^{1,2,3}$ MAO CHEN, ${ }^{2,4}$ HILDA L. COLLINS, ${ }^{2}$ DAVID ONSTAD,${ }^{5}$ RICK ROUSH,${ }^{6}$ \\ QINGWEN ZHANG ${ }^{1}$ AND ANTHONY M. SHELTON ${ }^{2}$
}

\begin{abstract}
J. Econ. Entomol. 105(2): 354-362 (2012); DOI: http://dx.doi.org/10.1603/EC11299
ABSTRACT In the laboratory and in cages in the greenhouse, we evaluated the toxicity of two insecticides (lambda-cyhalothrin and spinosad) on the parasitoid, Diadegma insulare (Cresson), and the predator, Coleomegilla maculate (DeGeer), both natural enemies of the diamondback moth, Plutella xylostella (L.). Lambda-cyhalothrin was very toxic to both natural enemies. Spinosad was less toxic to C. maculata adults and larvae, and slightly toxic to D. insulare. Both natural enemies suppressed P. xylostella populations in cages with $80 \%$ spinosad-treated and $20 \%$ nontreated plants; such suppression was not seen when lambda-cyhalothrin was used. Using broccoli, Brassica oleracea L. variety italica, a common host for P. xylostella, we also studied direct and indirect effects of both natural enemies in the presence and absence of the two insecticides and to different $P$. xylostella genotypes: resistant to the insecticide, susceptible, or heterozygous. Neither natural enemy could distinguish host genotype if $P$. xylostella were feeding on nontreated plants. They could also not distinguish between larvae feeding on spinosad-treated plants and nontreated plants, but $D$. insulare could distinguish between larvae feeding on lambda-cyhalothrin treated and nontreated plants. Our studies suggest that lambda-cyhalothrin has direct toxicity to these two natural enemies, can affect their host foraging and acceptance of $P$. xylostella and consequently would not be compatible in conserving these natural enemies in a program for suppression of $P$. xylostella. In contrast, our studies suggest that treatment with spinosad has much less effect on these natural enemies and would allow them to help suppress populations of P. xylostella. These findings are discussed in relation to the evolution of insecticide resistance and suppression of the pest populations.
\end{abstract}

KEY WORDS insecticide, resistance, host genotype, diamondback moth, biological control

The diamondback moth, Plutella xylostella (L.) (Lepidoptera: Plutellidae), is the most destructive insect pest of brassica crops in many parts of the world (Talekar and Shelton 1993, Grzywacz et al. 2010). This insect is now present wherever brassica crops are grown and is considered the most widely distributed of all Lepidoptera (Shelton 2004). Use of insecticides remains the main control strategy for P. xylostella because insecticides are easy to apply and often are cost-effective (Talekar and Shelton 1993). Unfortunately, some P. xylostella populations have evolved resistance to almost every insecticide class applied in the field, including pyrethroids, carbamates, or-

\footnotetext{
${ }^{1}$ Department of Entomology, China Agricultural University, Beijing, 100193, China.

${ }^{2}$ Corresponding author, e-mail: liuxiaoxia611@cau.edu.cn.

${ }^{3}$ Department of Entomology, Cornell University/New York State Agricultural Experiment Station, Geneva, NY 14456.

${ }^{4}$ Current address: GG3E, Monsanto Company, Chesterfield, MO 63017.

${ }^{5}$ National Soybean Research Center, University of Illinois, Urbana, IL 61801 .

${ }^{6}$ Melbourne School of Land and Environment, Parkville Campus, University of Melbourne, Victoria 3010, Australia.
}

ganophosphates, spinosyns, avermectins, neonicotinoids, pyrazoles, and oxadiazines (Zhao et al. 2006, Grzywacz et al. 2010).

Biological control agents can be an integral component of integrated pest management (IPM) programs because they help suppress insect pest populations in agricultural ecosystems (Tillman and Mulrooney 2000, Sarfraz et al. 2005). Identification and conservation of such natural enemies has been identified as a key strategy needed for control of $P$. xylostella (Grzywacz et al. 2010). It has been reported that before 1917 in the United States and Europe (Marsh 1917, Mustata 1992), P. xylostella populations were suppressed to a level below economic thresholds solely by natural enemies.

Diadegma insulare (Cresson) (Hymenoptera: Ichneumonidae) is a solitary larval endoparasitoid of $P$. xylostella and is one of its most important biocontrol agents (Shelton et al. 2002). In North America, parasitism by $D$. insulare often exceeds $70 \%$ in the field ( $\mathrm{Xu}$ et al. 2001, Hutchison et al. 2004). Coleomegilla maculata DeGeer (Coleoptera: Coccinellidae) is a common predator of aphids, thrips and eggs, and larvae of Lep- 
idoptera in many cropping systems throughout the United States (Roger et al. 2000). Larvae of all four instars, as well as adults, have been used widely in biological control programs (Rondon et al. 2006).

Insecticides remain important components of IPM programs for P. xylostella (Talekar and Shelton 1993, Grzywacz et al. 2010), despite the occurrence of resistant $P$. xylostella populations in some areas. Some newer insecticides are promoted as being softer on natural enemies and may be incorporated into IPM programs more readily. For example, spinosad is in the naturalyte class of insecticides and classified as a reduced risk insecticide (Williams et al. 2003). It is primarily absorbed in the gut and kills by causing rapid excitation of the insect nervous system (Salgado 1998). It has been registered for use on over 180 crops in the United States and in over 35 countries for control of caterpillars, beetles, leafminers, and thrips (Zhao et al. 2002). In contrast, lambda-cyhalothrin is a broad-spectrum pyrethroid insecticide with a long residual activity against many economically important agricultural pests, especially Lepidoptera (Liu et al. 1981).

Although these insecticides are used for managing P. xylostella populations in the field, they may also be detrimental to natural enemies. Although spinosad is generally considered nontoxic to natural enemies, some studies have reported it may be toxic to parasitoids (Murray and Lloyd 1997, Ruberson and Tillman 1999, Cossentine et al. 2010). In contrast, lambdacyhalothrin is generally considered very toxic to beneficial insects (Tillman 1995, Ruberson and Tillman 1999) and has been shown to be toxic to $D$. insulare (Xu et al. 2001).

In this study, we compared the direct and indirect toxicity of the two insecticides, spinosad and lambdacyhalothrin, on D. insulare and C. maculata. We also investigated the potential for more subtle effects by examining the host foraging and host acceptance behavior of both natural enemies in the presence or absence of the insecticides. This was done by determining whether either natural enemy could discriminate between different genotypes of $P$. xylostella (insecticide resistant [RR], susceptible [SS], or heterozygous [RS] individuals) and insecticidetreated or nontreated plants. Additionally, we conducted a series of large cage experiments in greenhouses over three generations of $P$. xylostella to determine how these insecticides, combined with $D$. insulare or C. maculata, affected the evolution of resistance to the insecticide.

\section{Materials and Methods}

Insects. Five strains of $P$. xylostella were used: 1) Pearl-RR strain, which is resistant to spinosad (Zhao et al. 2006); 2) Waipio-RR strain, which is resistant to lambda-cyhalothrin (Chen et al. 2008); 3) Geneva 88-SS strain, a susceptible strain that has been maintained on a wheat germ-casein artificial diet for over 500 generations (Shelton et al. 1991) without any changes in susceptibility; 4) Pearl-RS strain, which was created by crossing Pearl-RR with Geneva 88-SS, and: 5) Waipo-RS strain, which was created by crossing Waipo-RR with Geneva 88-SS. All strains were reared on an artificial diet and maintained in a climatic chamber at $27 \pm 1^{\circ} \mathrm{C}, 50 \pm 10 \% \mathrm{RH}$, and 16:8 L:D. The C. maculata originated from a laboratory population maintained by Pioneer Hi-Bred International, Inc. (Johnston, IA) and were reared on decapsulated eggs of brine shrimp, Artemia franciscana (Brine Shrimp Direct, Ogden UT) and a 1.5\% agar solution provided separately. All stages of the insects were maintained in a climatic chamber at $27 \pm 1^{\circ} \mathrm{C}, 50 \pm 10 \% \mathrm{RH}$ and $16: 8$ L:D. The population of $D$. insulare was originally fieldcollected in Florida and subsequently reared for $>30$ generations in our greenhouse, according to the procedures of Xu et al. (2001).

Insecticides and Plants. Commercial formulations of two insecticides were used: spinosad (SpinTor 2 SC, DowAgroSciences, Indianapolis, IN) and lambda-cyhalothrin (Warrior T, Syngenta Crop Protection, Greensboro, NC). Plants were treated with labeled field rates, converted to parts per million (90 ppm for spinosad and $80 \mathrm{ppm}$ for lambda-cyhalothrin). To detect changes in resistance allele frequencies, diagnostic doses of $10 \mathrm{ppm}$ for spinosad (Zhao et al. 2002) and $20 \mathrm{ppm}$ for lambda-cyhalothrin (based on our preliminary experiment) were used. Potted broccoli plants, Brassica oleracea L. variety italic cultivar 'Packman,' with eight true leaves were sprayed with a small handheld sprayer at 280 liter/ha.

Discrimination by $D$. insulare and C. maculata on Different Genotypes of $\boldsymbol{P}$. xylostella. To determine whether the natural enemy could differentiate the genotype (related to insecticide susceptibility) of its host, choice tests were conducted in $1 \times 1 \times 1 \mathrm{~m}$ netted cages. Fifty $P$. xylostella second instars (either Pearl-RR, RS, and SS or Waipio-RR, RS, and SS) of a single genotype were placed on an untreated broccoli leaf, with its petiole inserted in a $100 \mathrm{ml}$ flask filled with water $1 \mathrm{~d}$ before being exposed to each natural enemy. For each set of experiments (only one insecticide was examined per set) three flasks, each with a different genotype of $P$. xylostella (RR, RS, or SS), were placed in a triangle with equal distance $(80 \mathrm{~cm})$ between the flasks. Based on the results of our preliminary experiments, we decided to use two pairs of newly emerged $D$. insulare adults which were put into a Plexiglas cylinder cage $(10 \times 10 \times 20 \mathrm{~cm})$ with sugar water and allowed to mate for $3 \mathrm{~d}$. Then the two pairs of 3-d-old adult $D$. insulare were released in the center of the triangle in each cage. A flask of $10 \%$ sugar solution with a cotton wick was placed in the center of the triangle in each cage as a food source for $D$. insulare. After $48 \mathrm{~h}$, all P. xylostella larvae were removed from the cage and transferred to cups containing artificial diet (Shelton et al. 1991) and allowed to develop into P. xylostella adults or D. insulare adults. All 50 larvae from one leaf were placed in one cup. Parasitism rates [\% parasitism $=$ (number of $D$. insularel (number of $D$. insulare + number of $P$. xylostella $) * 100$ ] associated with $D$. insulare on each genotype of $P$. xylostella were recorded. Each treatment (cage) was repli- 
cated five times for the Pearl strains and four times for Waipio strains.

A similar choice experiment was conducted for $C$. maculata. Forty P. xylostella second instars (either Pearl-RR, RS, and SS or Waipio-RR, RS, and SS) of a single genotype were placed on an unsprayed broccoli leaf, with its petiole inserted in a $100 \mathrm{ml}$ flask filled with water $1 \mathrm{~d}$ before being exposed to each natural enemy. One 30-ml cup with two 5-d old C. maculata adults (one female and one male) or three third-instars was placed in the center of the cage. Then the cup's cover was removed to free the C. maculata within the cage. Three cages with 40 P. xylostella second instars, but without C. maculata, served as controls to determine the number of missing or dead P. xylostella larvae. After $48 \mathrm{~h}$, the number of remaining $P$. xylostella larvae were counted in the cages. Predation rates [\% predation $=$ (initial number of $P$. xylostella - number of remaining larvae - number of missing or dead larvae) / initial number of $P$. xylostella $\times 100$ ] were recorded. The treatment for C. maculata larvae was replicated six times and the adult treatment four times.

Discrimination by D. insulare on Different Genotypes of P. xylostella on Lambda-Cyhalothrin or Spinosad-Treated Plants Hosting Different Genotypes of $\boldsymbol{P}$. xylostella. To evaluate whether the parasitoids could discriminate between insecticide-treated plants hosting different genotypes of $P$. xylostella, a $2 \times 3$ design [ (plant types: insecticide treated or not $) \times(P$. xylostella genotypes: RR, RS, and SS) ] was used. Individual leaves were removed from the plant and treated with an insecticide or left untreated as a control. Each cage $(1 \times 1 \times 1 \mathrm{~m})$ had six treatments: PearlRR, Pearl- RS, SS on a spinosad-treated leaf and the same genotypes on untreated leaves. Each treatment had 50 P. xylostella second instars (RR, RS, or SS) on each leaf. The six leaves in flasks were placed randomly in a rectangle with equal distance $(50 \mathrm{~cm})$ between the flasks. The P. xylostella larvae were allowed to feed for $1 \mathrm{~d}$ before being exposed to $D$. insulare. Four pairs of newly emerged D. insulare adults were put into a Plexiglas cylinder cage $(10 \times$ $10 \times 20 \mathrm{~cm})$ with sugar water and allowed to mate for $3 \mathrm{~d}$. Then the four pairs of 3-d-old $D$. insulare were released into the center of each cage. After $48 \mathrm{~h}, P$. xylostella larvae were recovered and transferred to cups containing artificial diet and allowed to develop into $P$. xylostella adults or D. insulare adults, as described above. Parasitism rates $(\%)$ associated with $D$. insulare on each genotype of $P$. xylsotella were recorded. The six treatments were replicated six times.

A similar experiment was conducted with lambdacyhalothrin. Each cage $(1 \times 1 \times 1 \mathrm{~m})$ contained six treatments: Waipio - RR, Waipio - RS, SS on lambdacyhalothrin-treated leaves and untreated leaves, respectively. Each treatment had 50 P. xylostella second instars (RR, RS, or SS) on each leaf and four pairs of 3 -d-old $D$. insulare were released into the cage. Parasitism rates on each genotype of $P$. xylostella were recorded. The six treatments were replicated six times.

Discrimination by C. maculata on Spinosad-Treated Plants or Untreated Plants Hosting Resistant Geno- types of P. xylostella. Forty P. xylostella Pearl-RR second instars were placed on an untreated broccoli leaf and another 40 P. xylostella Pearl-RR second instars were placed on a spinosad-treated leaf. Each leaf petiole was inserted into a $100 \mathrm{ml}$ flask filled with water $1 \mathrm{~d}$ before being exposed to a predator. One 30-ml cup with two C. maculata adults (one female and one male) or two third-instars was put in the center of the cage, as described above. Then the cup's cover was removed to free the C. maculata within the cage. After $48 \mathrm{~h}$, the number of remaining larvae was counted. Three cages with 40 P. xylostella second instars, but without C. maculata, served as controls to determine the number of missing or dead P. xylostella larvae. Predation rates $[\%$ predation $=$ (initial number of $P$. xylostella - number of remaining larvae - number of missing or dead larvae)/initial number of P. xylostella $\times 100$ ] were recorded. The experiment was replicated six times.

Contact Toxicity of Spinosad and Lambda-Cyhalothrin to D. insulare and C. maculata. A broccoli leaf was dipped into a solution of spinosad at $90 \mathrm{ppm}$ or lambda-cyhalothrin at $80 \mathrm{ppm}$ and its petiole was inserted into a $100 \mathrm{ml}$ flask filled with water and air-dried for $1 \mathrm{~h}$. Then the treated leaf was placed into a Plexiglas cylinder cage $(10 \times 10 \times 20 \mathrm{~cm})$ and ten 2 - to 3-d-old D. insulare females or ten 7-d-old C. maculata males or females were released into the cylinder cage. A broccoli leaf dipped into a nonionic surfactant served as the control. Corrected mortality $(=$ (mortality rate of treated parasitoids or predators - mortality rate of control)/(1-mortality rate of control) was calculated after $24 \mathrm{~h}$ (Abbott 1925).

Effect of Spinosad-Treated and Lambda-Cyhalothrin Treated Plants on D. insulare and C. maculata Populations in a Greenhouse Cage Trial. The experiment was conducted in cages in greenhouses with the temperature ranging from $20^{\circ}$ to $27^{\circ} \mathrm{C}$ during the course of the experiment. The experiment was conducted over three generations of $P$. xylostella or around $70 \mathrm{~d}$. Each cage was $1.8 \mathrm{~m}$ long $\times 0.9 \mathrm{~m}$ wide $\times$ $1.7 \mathrm{~m}$ high and constructed of nylon netting. Four treatments were included: 1) $80 \%$ spinosad-treated broccoli and $20 \%$ untreated broccoli plants with $D$. insulare; 2) $80 \%$ spinosad-treated broccoli and $20 \%$ untreated broccoli plants with C. maculata; 3) $80 \%$ lambda-cyhalothrin treated broccoli and $20 \%$ untreated broccoli plants with D. insulare; 4) $80 \%$ lambda-cyhalothrin treated broccoli and $20 \%$ untreated broccoli plants with C. maculata. The $20 \%$ untreated plants represented a refuge for $P$. xylostella and the natural enemies. Such refuges occur naturally in an agricultural setting because of poor spray coverage or weed hosts, or could be deliberately incorporated as a tactic to preserve natural enemies or susceptible alleles in the pest population.

The goal of this study was to assess $P$. xylostella, $D$. insulare, and C. maculata population abundance in the cages with insecticide-treated and untreated plants and to follow the evolution of insecticide resistance in the P. xylostella populations. Therefore, two populations of P. xylostella, each with a known insecticide 
Table 1. Parasitism by $D$. insulare and predation by $C$. maculataon different genotypes of $P$. xylostella feeding on untreated broccoli

\begin{tabular}{|c|c|c|c|c|c|c|}
\hline & \multicolumn{3}{|c|}{ Pearl } & \multicolumn{3}{|c|}{ Waipio } \\
\hline & $\mathrm{RR}$ & $\mathrm{RS}$ & SS & $\mathrm{RR}$ & RS & SS \\
\hline $\begin{array}{l}\text { Parasitism \% } \\
\text { Predation \% }\end{array}$ & $35.6 \pm 12.93 \mathrm{a}$ & $48.5 \pm 8.45 a$ & $48.9 \pm 9.01 \mathrm{a}$ & $38.5 \pm 12.53 \mathrm{a}$ & $39.6 \pm 13.56 \mathrm{a}$ & $49.5 \pm 11.72 \mathrm{a}$ \\
\hline Adult & $58.1 \pm 6.56 \mathrm{a}$ & $61.9 \pm 7.10 \mathrm{a}$ & $44.4 \pm 2.37 \mathrm{a}$ & $59.4 \pm 6.24 \mathrm{a}$ & $45.6 \pm 3.29 \mathrm{a}$ & $41.3 \pm 5.25 \mathrm{a}$ \\
\hline Larvae & $67.8 \pm 4.36 \mathrm{a}$ & $51.1 \pm 6.25 \mathrm{a}$ & $50.6 \pm 6.29 \mathrm{a}$ & $66.7 \pm 4.13 \mathrm{a}$ & $60.0 \pm 8.12 \mathrm{a}$ & $62.2 \pm 7.63 \mathrm{a}$ \\
\hline
\end{tabular}

Means $( \pm$ SEM) within the same row followed by a same letter are not significantly different $(P>0.05$; Tukey test); Pearl and Waipio RR strains are resistant to spinosad and lambda-cyhalothrin, respectively. The SS populations are the Geneva 88 strains, whereas the RS strains resulted from the cross of a RR strain and the Geneva SS strain.

resistance allele frequency, were needed and these synthetic populations were developed in a manner similar to that described by Zhao et al. (2005). One population was created by releasing 80 Pearl-RS moths and $120 \mathrm{G} 88$ (S) moths into a Plexiglas cylinder cage $(10 \times 10 \times 20 \mathrm{~cm})$ to prepare a population for treatments 1 and 2 . The other was created by releasing 80 Waipio RS and 120 G88 moths into a similar Plexiglas cylinder cage to prepare a population for treatments 3 and 4 . The total number of moths was 200 with a 1:1 ratio of female and male moths for each population. Eggs were collected from the cylinder cage and put on artificial diet to rear $\mathrm{F} 1$ larvae. We used $\approx 1,000 \mathrm{~F}_{1}-\mathrm{F}_{3}$ moths to produce $\mathrm{F}_{2}-\mathrm{F}_{4}$ eggs of the synthetic population. The expected resistant allele frequency of both populations was 0.2 . The actual survival of unselected $F_{3}$ larvae was $0.95 \%$ on spinosad-treated plants and $0.67 \%$ on lambda-cyhalothrin treated plants. Based on the actual survival, the actual initial allele frequency (square root of survival rate) at the start of the experiment was estimated to be 0.08 for spinosad resistance and 0.10 for lambdacyhalothrin resistance. Two hundred $\mathrm{F}_{4}$ pupae of each synthetic $P$. xylostella population were released into each cage. According to results from our preliminary experiments, we used three pairs of newly emerged $D$. insulare adults that we placed into a Plexiglas cylinder cage $(10 \times$ $10 \times 20 \mathrm{~cm}$ ) with sugar water to mate for $3 \mathrm{~d}$. Then the three pairs of $D$. insulare or three pairs of $C$. maculata that had emerged within the week were released into each cage when $P$. xylostella larvae were mostly second instars.

There were three replications (=cages) for each treatment for a total of 12 cages, and each cage contained 15 plants (12 insecticide-treated plants plus three untreated plants). Individual plants were replaced at each insect generation or when the plants were severely defoliated and did not provide sufficient food for the P. xylostella population. The number of $C$. maculata and P. xylostella larvae (primarily third or fourth instars) and pupae on the broccoli plants was counted every generation when larval and pupal densities reached a plateau. The number of $D$. insulare pupae on broccoli plants was counted $3 \mathrm{~d}$ after most of P. xylostella pupated.

To document changes in resistance allele frequency, $\approx 25$ larvae from the untreated plants were collected from each cage at the third generation and reared on artificial diet (Shelton et al. 1991) to the adult stage. The $F_{1}$ offspring of the adults were reared on artificial diet to the second-instar. Then they were bioassayed in 30-ml plastic cups using insecticidetreated cabbage leaf disks with the respective discriminating doses of $10 \mathrm{ppm}$ for spinosad and $20 \mathrm{ppm}$ for lambda-cyhalothrin. Untreated cabbage leaf disks were used as controls. In total, 100 larvae were tested (10 replications, 10 larvae/rep) for each cage. Survival was determined after $24 \mathrm{~h}$ at $27 \pm 1^{\circ} \mathrm{C}$.

Statistical Analysis. Percent parasitism and predation rates were transformed by using the arcsine square-root, then were analyzed using one-way ANOVA, and differences between treatment means were separated using Tukey's test at a 5\% level of significance. The statistical analyses were conducted using SPSS 17.0 Windows (1998) (SPSS, Chicago, IL).

Populations of P. xylostella, D. insulare, and C. maculata were transformed by $\log (x+1)$ and analyzed using repeated measure analysis of variance (ANOVA) in the SAS LIFETEST procedure, and difference between spinosad-treated cages and lambda-cyhalothrin treated cages were separated based on $t$-test $(P<0.05$ or $P<0.01)$ using SAS version six package (SAS Institute 2001).

\section{Results}

Discrimination by D. insulare and C. maculata on Different Genotypes of $\boldsymbol{P}$. xylostella. For the Pearl and Waipio strains, parasitism rates associated with $D$. insulare with RR, RS, and SS genotypes on untreated broccoli plants were not significantly different (Pearl: $F=0.543, \mathrm{df}=12, P=0.595$; Waipio: $F=0.229, \mathrm{df}=$ $9, P=0.800$; Table 1$)$. For both strains, there were no significant differences in predation rates associated with C. maculata adults (Pearl: $F=2.570, \mathrm{df}=9, P=$ 0.131; Waipio: $F=3.470, \mathrm{df}=9, P=0.076$ ) or larvae (Pearl: $F=2.944, \mathrm{df}=15, P=0.083$; Waipio: $F=0.245$, $\mathrm{df}=15, P=0.786)$.

Discrimination by $D$. insulare on Different Genotypes of $\boldsymbol{P}$. xylostella on Lambda-Cyhalothrin or Spinosad-Treated Plants Hosting Different Genotypes of P. xylostella. Because RS and SS larvae did not survive on spinosad-treated or lambda-cyhalothrin treated broccoli plants, no parasitoids emerged. However, parasitism rates because of $D$. insulare were similar when RR larvae $(62.9 \pm 7.5 \%)$ fed on spinosad-treated broccoli, and RR $(67.0 \pm 4.7 \%)$, RS $(62.7 \pm 11.5 \%)$, and SS $(66.2 \pm 3.6 \%)$ larvae fed on untreated broccoli plants $(F=0.088 ; \mathrm{df}=12 ; P=0.965)$. In contrast, for lambda-cyhalothrin, parasitism rates were $62.1 \pm 6.4$, 


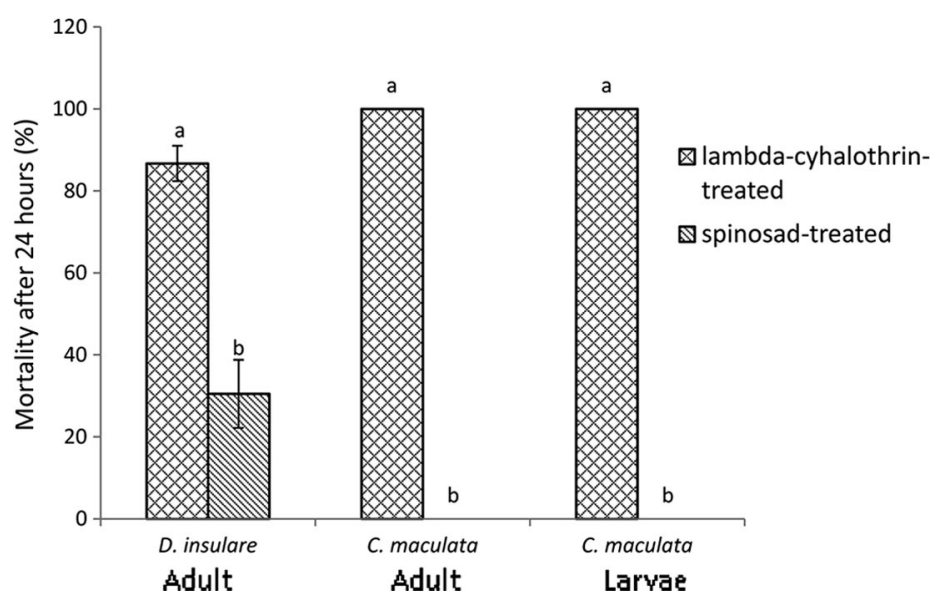

Fig. 1. Direct mortality of D. insulare and C. maculata treated with spinosad or lambda-cyhalothrin after $24 \mathrm{~h}$. Means $( \pm \mathrm{SE})$ with different letters are significantly different based on Tukey’s test $(P<0.05)$.

$60.2 \pm 3.9$, and $59.8 \pm 6.9 \%$ when Waipio-RR, WaipioRS, and SS larvae fed on untreated broccoli, but $20.3 \pm$ $5.8 \%$ when Waipio-RR larvae fed on treated broccoli. There were significant differences among the six treatments $(F=23.930$; $\mathrm{df}=30 ; P<0.0001)$.

Discrimination by C. maculata on Spinosad-Treated Plants or Untreated Plants Hosting Resistant Genotypes of $\boldsymbol{P}$. xylostella. Predation by C. maculata adult was $57.7 \pm 6.4 \%$ and $55.4 \pm 3.2 \%$ when they fed on RR P. xylostella reared on spinosad-treated or untreated plants, respectively. Predation by C. maculata larvae was $67.9 \pm 3.2 \%$ and $60.0 \pm 5.8 \%$, respectively. There were no significant differences in predation by $C$. maculata adults and larvae on sprayed or unsprayed broccoli plants (adult: $t=0.415$, df $=5, P=0.695$; larvae: $t=1.327$, $\mathrm{df}=5, P=0.242$ ).

Contact Toxicity of Spinosad and Lambda-Cyhalothrin to D. insulare and C. maculata. Lambda-cyhalothrin was toxic to D. insulare and C. maculata with mortality rates of $86.7 \pm 4.5 \%$ for D. insulare and $100 \%$ for C. maculata adults and larvae (Fig. 1). The mortality rate for $D$. insulare was $30.5 \pm 8.7 \%$ when they were exposed to a spinosad-treated leaf. There was no mortality of C. maculata adults and larvae when exposed to spinosad.

Effect of Spinosad-Treated and Lambda-Cyhalothrin Treated Plants on D. insulare and C. maculata Populations in a Greenhouse Cage Trial. The P. $x y$ lostella populations in the lambda-cyhalothrin treated cages with $D$. insulare were significantly higher than in the spinosad-treated cages for the first generation $(t=$ $-4.00 ; P=0.0317)$, but there were no significant differences $(F=3.25$; $\mathrm{df}=4 ; P=0.1458)$ in the second and third generations (Fig. 2A). However, P. xylostella populations for both treatments decreased significantly with increasing generations (generations: $F=41.62$; $\mathrm{df}=8$; $P<0.0001)$. The $D$. insulare population in the spinosadtreated cages was significantly higher than in the lambdacyhalothrin treated cages in the second generation $(F=$ 10.10, $\mathrm{df}=4, P=0.0336$; Fig. $2 \mathrm{~B}$ ). There were significant differences in the ratio of $D$. insulara/P. xylostella be- tween spinosad treated and lambda-cyhalothrin treated cages $(F=38.99$, df $=4, P=0.0034$; Fig. $2 \mathrm{C}$ ), again suggesting that spinosad was less harmful than lambdacyhalothrin to $D$. insulare. The ratios increased significantly with increasing generations $(F=106.77$; df $=8$; $P<0.0001)$, suggesting longer-term conservation of this parasitoid in the system.

Populations of P. xylostella in the lambda-cyhalothrin treated cages with C. maculata were significantly higher $(F=113.48$; $\mathrm{df}=4 ; P=0.0004)$ than in the spinosad-treated cages in the first three generations (Fig. 3A). No C. maculata survived in the lambdacyhalothrin treated cages (Fig. 3B). However, $C$. maculata survived in the spinosad-treated cages and were significantly higher $(F=17.02$; df $=8 ; P=$ $0.0013)$ in all three generations. The ratio of C. maculata/P. xylostella populations significantly increased $(F=123.11 ; \mathrm{df}=8 ; P<0.0001)$ with increasing generations (Fig. 3C), again indicating the safety of spinosad to C. maculata.

Evolution of insecticide resistance in P. xylostella population was also assessed in the large cage experiment. Survival of P. xylostella was $1.0 \pm 0.7 \%$ on spinosad-dipped cabbage leaves after three generations of selection in the spinosad-treated cages with $C$. maculata. Because $85 \%$ of the collected larvae were parasitized by $D$. insulare in the spinosad-treated cages, only 12 P. xylostella pupae were found. Survival of the offspring larvae was $0 \%$ on spinosad-dipped cabbage leaves. Spinosad resistance allele frequency in P. xylostella was around 0.1, almost the same as in the beginning of the experiment. In contrast, larval survival was $17.0 \pm 3.9 \%$ and $12.5 \pm 3.3 \%$ on lambdacyhalothrin-dipped cabbage leaves in the lambda-cyhalothrin treated cages with $D$. insulare and lambdacyhalothrin treated with C. maculata, respectively. Resistance allele frequency of $P$. xylostella for lambdacyhalothrin resistance was 0.36 in the cages with $D$. insulare and 0.30 with C. maculata, which was a significant $(F=11.247$; $\mathrm{df}=2 ; P<0.0001)$ increase over three generations of selection. 

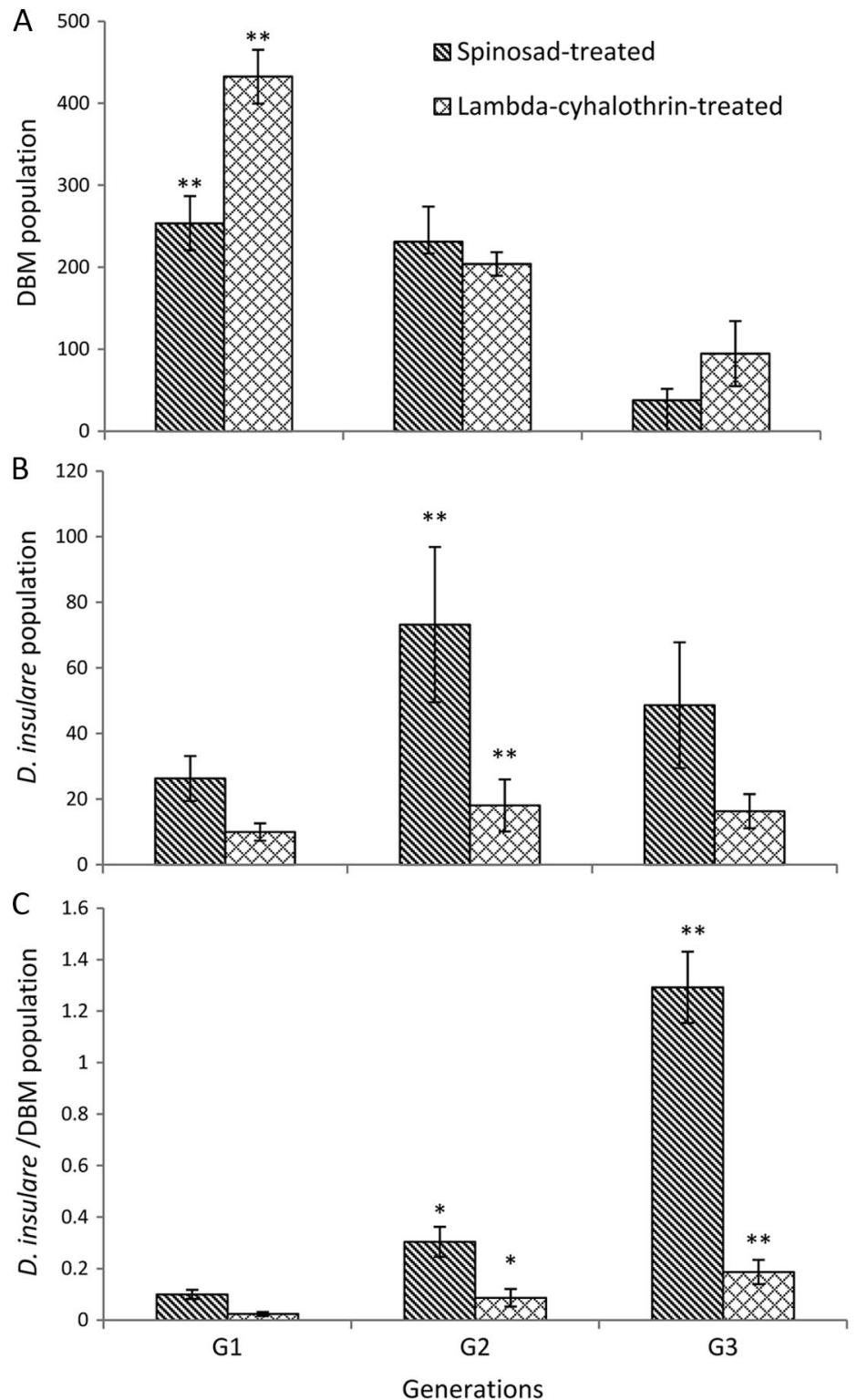

Fig. 2. (A) P. xylostella (DBM) population abundance, (B) D. insulare population abundance, (C) ratio of D. insulare/ DBM population abundance. Means $( \pm \mathrm{SE}$ ) marked with “*” or “**” are significantly different between spinosad-treated cages and lambda-cyhalothrin treated cages based on $t$-test $(P<0.05 ; P<0.01)$.

\section{Discussion}

Insecticides and biological control can be effective in reducing insect pest populations. Our current study focused on direct and indirect effects of two important insecticides on natural enemies of $P$. xylostella, $D$. insulare, and C. maculata. However, our study also investigated potential interactions between resistant genotypes and natural enemies. Such effects could alter resistance evolution if natural enemies displayed a preference for a particular genotype. In our current study, resistance allele frequencies in the spinosadtreated cages did not change appreciably over three generations of selection, but resistance significantly increased in the lambda-cyhalothrin treated cages. We conclude that resistance evolution in the lambdacyhalothrin sprayed treatment occurred faster than in the spinosad treatment because of its deleterious effects on natural enemies. Further studies over additional generations should be conducted to verify this trend.

Because field populations of $P$. xylostella have been challenged by many insecticides and developed resistance to some, one would expect to find resistant, heterozygous and susceptible larvae in the field at any 

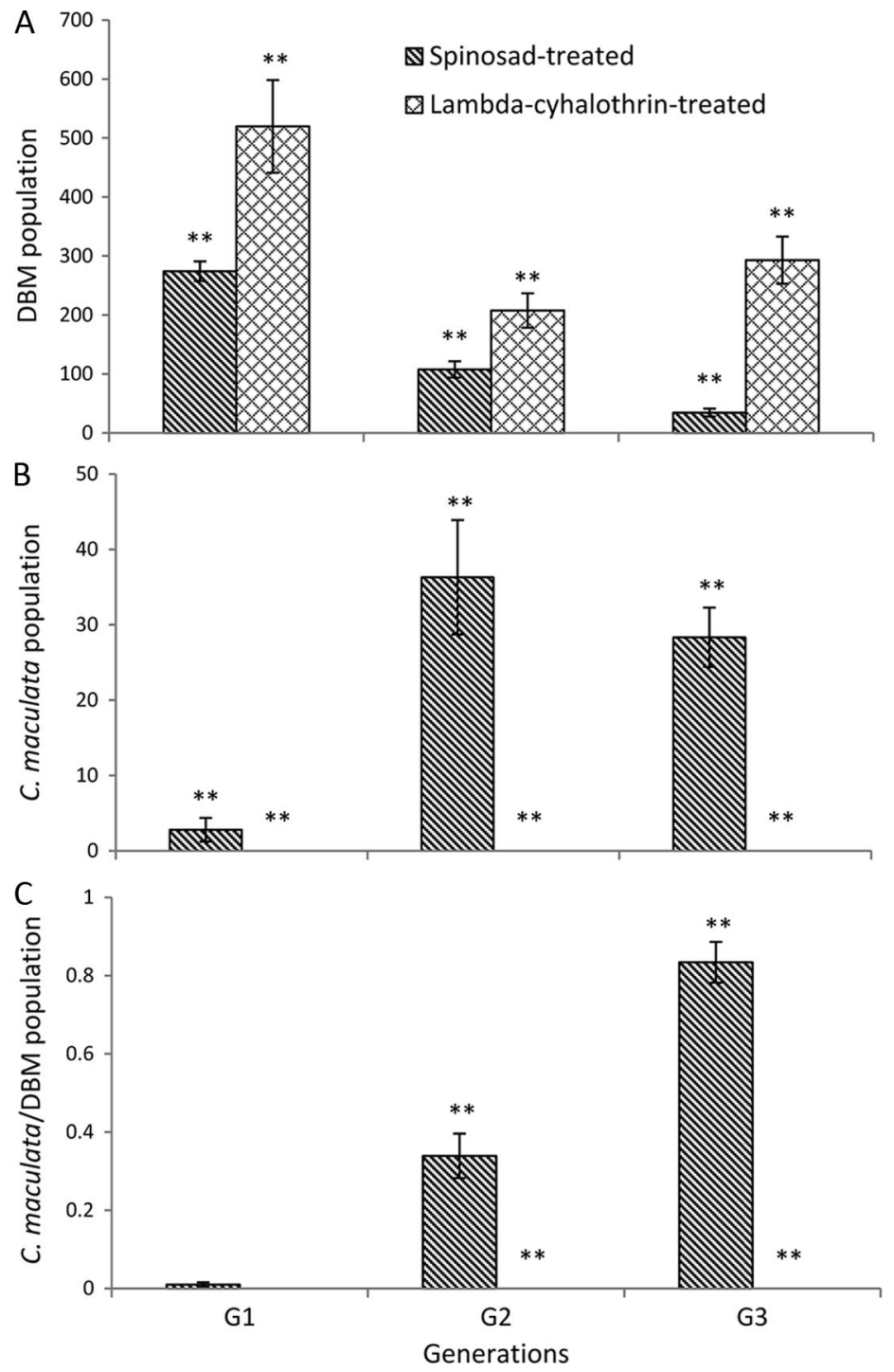

Fig. 3. (A) P. xylostella (DBM) population abundance, (B) C. maculata population abundance, (C) ratio of C. maculata/ DBM population abundance. Means $( \pm \mathrm{SE})$ marked with “**” are significantly different between spinosad-treated cages and lambda-cyhalothrin treated cages based $t$-test $(P<0.01)$.

given time. If natural enemies have a preference for resistant individuals, then this would reduce the likelihood of the population becoming resistant to the insecticide (Gould et al. 1991). Our results indicate that parasitism rates of $D$. insulare and predation rates of C. maculata are not significantly different regardless of genotype (Table 1). Therefore, we conclude that both natural enemies do not discriminate between different host genotypes. If they had preferred one genotype, this would have altered resistance evolution (Onstad 2008, p. 219).

In this study, we determined the direct and indirect effects of two insecticides on $D$. insulare. For the spinosad-treated leaves, parasitism rates were not significantly different when resistant $P$. xylostella fed on treated broccoli leaves or when RR, RS, and SS hosts fed on untreated broccoli leaves. In fact, no parasitoids emerged when RS and SS P. xylostella fed on treated broccoli leaves because the host (P. xylostella) did not survive. For lambda-cyhalothrin treated leaves, parasitism was significantly lower when RR P. xylostella fed on treated broccoli, compared with RR, RS, and SS $P$. xylostella that fed on untreated broccoli. Furthermore, there were no interactions for treatment and P. xylostella genotypes on the spinosad-treated leaves, but the parasitoid could discriminate between treated and untreated lambda-cyhalothrin leaves. We believe this is the first study to address the effects of insecticides on the foraging behavior and host acceptance of $D$. insulare. For C. maculata, adults and larvae did not show any preference between spinosad-treated and untreated leaves. 
Spinosad is classified as an environmentally and toxicologically reduced-risk insecticide by the United States Environmental Protection Agency (EPA 1997). Our results showed that spinosad was nontoxic to $C$. maculata adults and larvae, but inhibited survival of $D$. insulare when the parasitoid contacted the broccoli treated with spinosad. Galvan et al. (2005a) reported that spinosad decreased survival of first instars of the ladybird Harmonia axyridis (Pallas), extended their development time, decreased their weight gain, and reduced oviposition under laboratory conditions. However, they found the density of $H$. axyridis larvae in sweet corn plots treated with spinosad did not significantly differ from untreated plots in the field (Galvan et al. 2005b).

Research has focused on the direct or indirect effects of insecticides, including spinosad, on $D$. insulare (Hill and Foster 2000, 2003; Xu et al. 2001, 2004; Cordero et al. 2007; Cossentine et al. 2010). Xu et al. (2004) showed that spinosad caused $100 \%$ mortality of $D$. insulare adults, but did not reduce adult emergence when $D$. insulare pupae were treated. Cordero et al. (2007) observed $\approx 80 \%$ mortality of $D$. insulare after $24 \mathrm{~h}$ at the field-use rates of spinosad. Hill and Foster (2000) reported spinosad caused $100 \%$ mortality of $D$. insulare $8 \mathrm{~h}$ after treatment under laboratory conditions. However, in a follow-up study, parasitism of $P$. xylostella larvae was not affected by spinosad application under field conditions (Hill and Foster 2003). In general, it appears that hymenopteran parasitoids are more susceptible to spinosad than predatory insects (Williams et al. 2003). Most of the above laboratory-based experiments were conducted in petri dishes, but we used larger cages $(10 \times 10 \times 20 \mathrm{~cm})$ that may have allowed higher survivorship. In our greenhouse experiments with spinosad-sprayed plants and $20 \%$ refuge plants, $>60 D$. insulare pupae were found in the second generation, although we released only three pairs of $D$. insulare adults at the beginning of the experiment. This again suggests the relative safety of spinosad to $D$. insulare.

That broad-spectrum pyrethroids are generally toxic to beneficial insects has been well documented by previous research (Tillman 1995; Ruberson and Tillman 1999; Tillman and Mulrooney 2000; Galvan et al. 2005a,b). We found the pyrethroid lambda-cyhalothrin to be highly toxic to both C. maculata and D. insulare. In the cages with $80 \%$ lambda-cyhalothrin treated plants and $20 \%$ refuge plants, no C. maculata were found for three generations. Although $>80 \%$ adult mortality of $D$. insulare was observed in the laboratory on lambda-cyhalothrin treated plants, some $D$. insulare adults survived and reproduced in the cages with $80 \%$ lambda-cyhalothrin treated plants and $20 \%$ refuge plants. More than 20 $D$. insulare adults were present at the second and third generations, but all were on refuge plants. Based on the above facts and low parasitism rates when RR P. xylostella fed on lambda-cyhalothrin treated plants, it may be that D. insulare could discriminate between lambda-cyhalothrin treated and untreated plants and avoid the former.

P. xylostella remains a pervasive and intransigent pest to manage using either synthetic insecticides or biological control alone (Shelton 2004). Our results (Fig. 3) indicate that P. xylostella populations re- mained high at the third generation with $80 \%$ lambdacyhalothrin treated plants and $20 \%$ untreated plants because all $C$. maculata were killed by lambda-cyhalothrin. However, P. xylostella population growth was reduced in the cages with $80 \%$ spinosad-treated plants and $20 \%$ nontreated plants when C. maculata were included. We found some $D$. insulare survived on refuge plants although lambda-cyhalothrin was highly toxic to the parasitoid (Fig. 2). Thus, a refuge to maintain natural enemies may be helpful when insecticides are used as a component of IPM.

In summary, both natural enemies could not distinguish host genotype if $P$. xylostella fed on untreated plants so this would not be a factor influencing the evolution of resistance in this system. Furthermore, they could not distinguish between spinosad-treated and untreated plants, but $D$. insulare could avoid lambda-cyhalothrin treated plants, which may influence the evolution of resistance. In general, we concluded that lambda-cyhalothrin was more disruptive to these two important natural enemies, and that appropriate treatment with spinosad can control P. xylostella and still be compatible with biological control by these two natural enemies. This in turn may help slow the evolution of resistance to spinosad.

\section{Acknowledgments}

We thank Yen Mei Cheung for technical assistance. This project was supported by the Biotechnology Risk Assessment Program Competitive Grant 2008-33120-19536 from the USDA National Institute of Food and Agriculture and the Special Research Projects for Developing Transgenic Plants (2011zx08011-002) in China.

\section{References Cited}

Abbott, W. S. 1925. A method of computing the effectiveness of an insecticide. J. Econ. Entomol. 18: 265-267.

Chen, M., J. Z. Zhao, H. L. Collins, E. D. Earle, J. Cao, and A. M. Shelton. 2008. A critical assessment of the effects of Bt transgenic plants on parasitoids. PLoS ONE 3: e2284. (doi:10.1371/journal.pone.0002284).

Cordero, R. J., J. R. Bloomquist, and T. P. Kuhar. 2007. Susceptibility of two diamondback moth parasitoids, Diadegma insulare (Cresson) (Hymenoptera: Ichneumonidae) and Oomyzus sokolowskii (Kurdjumov) (Hymenoptera: Eulophidae), to selected commercial insecticides. Biol. Control 42: 48-54.

Cossentine, J. E., C. L. Zurowski, and M. J. Smirle. 2010. Impact of spinosad on ichneumonid-parasitized Choristoneura rosaceana larvae and subsequent parasitoid emergence. Entomol. Exp. Appl. 136: 116-122.

(EPA) U.S. Environmental Protection Agency. 1997. Spinosad Pesticide. Fact sheet no. 501C. Environmental Protection Agency, Office of Pesticides and Toxic substances. (www.epa.gov).

Galvan, T. L., R. L. Koch, and W. D. Hutchison. 2005a. Effects of spinosad and indoxacarb on survival, development, and reproduction of the multicolored Asian lady beetle (Coleoptera: Coccinellidae). Biol. Control 34: $108-114$.

Galvan, T. L., R. L. Koch, and W. D. Hutchison. 2005b. Toxicity of commonly used insecticides in sweet corn and 
soybean to multicolored Asian lady beetle (Coleoptera: Coccinellidae). J. Econ. Entomol. 98: 780-789.

Gould, F., G. G. Kennedy, and M. T. Johnson. 1991. Effects of natural enemies on the rate of herbivore adaptation to resistant host plants. Entomol. Exp. Appl. 58: 1-14.

Grzywacz, D., A. Rossbach, A. Rauf, D. Russell, R. Srinivasan, and A. M. Shelton. 2010. Current control methods for diamondback moth and prospects for improved management with lepidopteran-resistant Bt vegetable brassicas in Asia and Africa. Crop Protect. 29: 68-79.

Hill, T. A., and R. E. Foster. 2000. Effect of insecticides on the diamondback moth (Lepidoptera: Plutella) and its parasitoid Diadegmainsulare (Hymenoptera: Ichneumonidae). J. Econ. Entomol. 93: 763-768.

Hill, T. A., and R. E. Foster. 2003. Influence of selected insecticides on the population dynamics of diamondback moth (Lepidoptera: Plutellidae) and its parasitoid, Diadegmainsulare (Hymenoptera: Ichneumonidae), in cabbage. J. Entomol. Sci. 38: 59-71.

Hutchison, W. D., E. C. Burkness, G. Pahl, and T. M. Hurley. 2004. Integrating novel technologies for cabbage IPM in the USA: value of on-farm research, pp. 371-379. In N. M. Endersby and P. M. Ridland (eds.), The management of diamondback moth and other crucifer pests. Proceedings of the Fourth International Workshop, 26-29 November 2001, Melbourne. Department of Natural Resources and Environment, Melbourne, Australia.

Liu, M. Y., Y. J. Teng, and C. N. Sun. 1981. Diamondback moth, resistance to several synthetic pyrethroids. J. Econ. Entomol. 74: 393-396.

Marsh, H. O. 1917. Life history of Plutella maculi pennis, the diamondback moth. J. Agric. Res. 10: 1-10.

Murray, D. A., and R. J. Lloyd. 1997. The effect of spinosad (Tracer) on arthropod pest and beneficial populations in Australian cotton, pp. 1087-1091. In Proceedings of Beltwide Cotton Conference, 6-10 January 1997, New Orleans, LA. National Cotton Council, Memphis, TN.

Mustata, G. 1992. Role of parasitoid complex in limiting the population of diamondback moth in Maldavia, Romania, pp 203-211. In N. S. Talekar (ed.), Proceedings of the 2nd International Workshop on Diamondback moth and other Crucifer Pests. Asian Vegetable Research and Development Center, Shanhua, Taiwan.

Onstad, D. W. 2008. The role of environment in insect resistance management, pp. 209-226, chapter 10. In D. W. Onstad (ed.), Insect resistance management: biology, economics and prediction. Academic Press, Oxford, United Kingdom.

Roger, C., D. Coderre, and G. Boivin. 2000. Differential prey utilization by the generalist predator Coleomegilla maculata lengi according to prey size and species. Entomol. Exp. Appl. 94: 3-13.

Rondon, S. I., J. F. Price, and D. J. Cantliffe. 2006. Developmental time, reproduction, and feeding of two subspecies of Coleomegilla maculata (Coleoptera: Coccinellidae) in the laboratory. Fla. Entomol. 89: 85-88.

Ruberson, J. R., and P. G. Tillman. 1999. Effect of selected insecticides on natural enemies in cotton: laboratory studies, pp. 1210-1213. In Proceedings, Beltwide Cotton Conferences, 3-7 January 1999, New Orleans, LA. National Cotton Council, Orlando, FL.

Salgado, V. L. 1998. Studies on the mode of action of spinosad: insect symptoms and physiological correlates. Pestic. Biochem. Physiol. 60: 91-102.
Sarfraz, M. A., A. B. Keddie, and L. M. Dosdall. 2005. Biological control of the diamondback moth, Plutella xylostella: a review. Biocontrol Sci. Tech. 15: 763-789.

SAS Institute. 2001. PROC user's manual, version 6th ed. SAS Institute, Cary, NC.

Shelton, A. M. 2004. Management of the diamondback moth: déjà vu all over again?, pp. 3-8. In N. M. Endersby and P. M. Ridland (eds.), The management of diamondback moth and other crucifer pests. Proceedings of the Fourth International Workshop, 26-29 November 2001. Melbourne. Department of Natural Resources and Environment, Melbourne, Australia.

Shelton, A. M., M. K. Kroening, W. T. Wilsey, and S. D. Eigenbrode. 1991. Comparative analysis of two rearing procedures for diamondback moth, Plutella xylostella (Lepidoptera: Plutellidae). J. Entomol. Sci. 26: 17-26.

Shelton, A. M., W. T. Wilsey, E. R. Hoebeke, and M. A. Schmaedick. 2002. Parasitoids of cabbage Lepidoptera in Central New York. J. Entomol. Sci. 37: 270-271.

SPSS. 1998. SPSS user's guide. SPSS Inc., Chicago, IL

Talekar, N. S., and A. M. Shelton. 1993. Biology, ecology, and management of the diamondback moth. Annu. Rev. Entomol. 38: 275-301.

Tillman, P. G., and J. E. Mulrooney, J. E. 2000. Effect of selected insecticides on the natural enemies Coleomegilla maculata and Hippodamia convergens (Coleoptera: Coccinellidae), Geocoris punctipes (Hemiptera: Lygaeidae), and Bracon mellitor, Cardiochiles nigriceps, and Cotesia mariginiventris (Hymenoptera: Braconidae) in cotton. J. Econ. Entomol. 93: 1638-1643.

Tillman, P. G. 1995. Susceptibility of Microplitis croceipes and Cardiochiles nigriceps (Hymenoptera: Braconidae) to field rates of selected cotton insecticides. J. Entomol. Sci. 30: 390-396.

Williams, T., J. Valle, and E. Vinuela. 2003. Is the naturally derived insecticide Spinosad compatible with insect natural enemies? Biocontrol Sci. Tech. 13: 459-475.

Xu, J. X., A. M. Shelton, and X. N. Cheng. 2001. Comparison of Diadegma insulare (Hymenoptera: Ichneumonidae) and Microplitis plutellae (Hymenoptera: Braconidae) as biological control agents of Plutella xylostella (Lepidoptera: Plutellidae): field parasitism, insecticide susceptibility, and host searching. J. Econ. Entomol. 94: 14-20.

Xu, Y. Y., T. X. Liu, G. L. Leibee, and W. A. Jones. 2004. Effects of selected insecticides on Diadegma insulare (Hymenoptera: Ichneumonidae), a parasitoid of Plutella xylostella (Lepidoptera: Plutellidae). Biocontrol Sci. Tech. 14: 713-723.

Zhao, J. Z., H. L. Collins, Y. X. Li, R. F. Mau, G. D. Thompson, M. S. Hertlein, J. T. Andaloro, R. Boyken, and A. M. Shelton. 2006. Monitoring of diamondback moth resistance to spinosad, indoxacarb and emamectin benzoate. J. Econ. Entomol. 99: 176-181.

Zhao, J. Z., J. Cao, H. L. Collins, S. L. Bates, R. T. Roush, E. D. Earle, and A. M. Shelton. 2005. Concurrent use of transgenic plants expressing a single and two Bacillus thuringiensis genes speeds insect adaptation to pyramides plants. Proc. Natl. Acad. Sci. U.S.A. 102: 8426-8430.

Zhao, J. Z., Y. X. Li, H. L. Collins, L. Gusukuma-Minuto, R.F.L. Mau, G. D. Thompson, and A. M. Shelton. 2002. Monitoring and characterization of diamondback moth (Lepidoptera: Plutellidae) resistance to Spinosad. J. Econ. Entomol. 95: 430-436.

Received 5 September 2011; accepted 30 January 2012. 